upper part of the chest the veins were rather large. $\mathrm{Dr}$. Coupland, under whose care the patient was, suspected the possibility of an aneurysm, and the patient was then examined by the Roentgen rays and a fluorescent screen. The result showed clearly that there was some enlargement of the first part of the aorta, and from the shape it seemed to indicate that the enlargement was fusiform rather than aaccular. The appearance is seen in Fig. 1, which shows that the shadow of the heart, instead of terminating at its base in the usual way, has its left border prolonged upwards along the left side of the sternum.

CASE 2.- This case was kindly brought to me by Sir Richard Douglas-Powell. The patient complained of pain in the chest with paroxysmal attacks of coughing and dyspnoea. Physical examination showed that there was a dull area over the upper part of the sternum. Examination by the Roentgen rays showed a shadow corresponding to this area of dulness (Fig. 2). The shadow was not very well marked and its

FIG. 2.

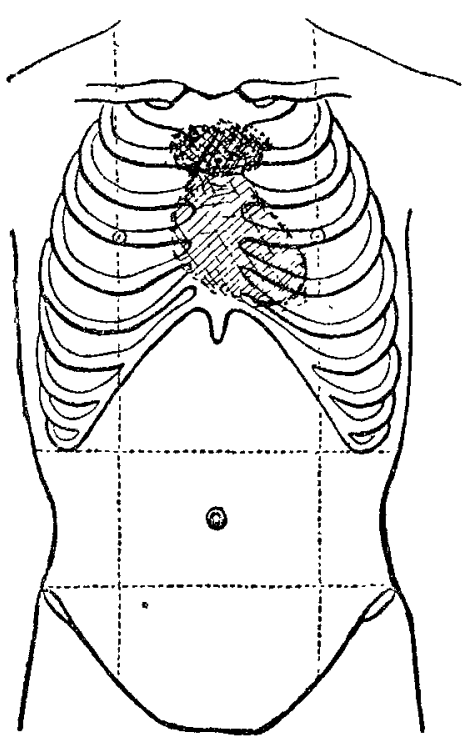

Showing the somewhat indefinite shadow at the level of the second ribs.

ontlines were irregular, but it was quite distinct. From its appearance and the various symptoms it was thought that there might be a mediastinal abscess, but subsequent events have made it probable that it is an aneurysm.

CASE 3.-This was a case of aneurysm which I saw on three different occasions with Dr. Bezly Thorne. The patient, a man, aged forty-two years, had signs and symptoms of an aneurysm situated probably in the third part of the arch of

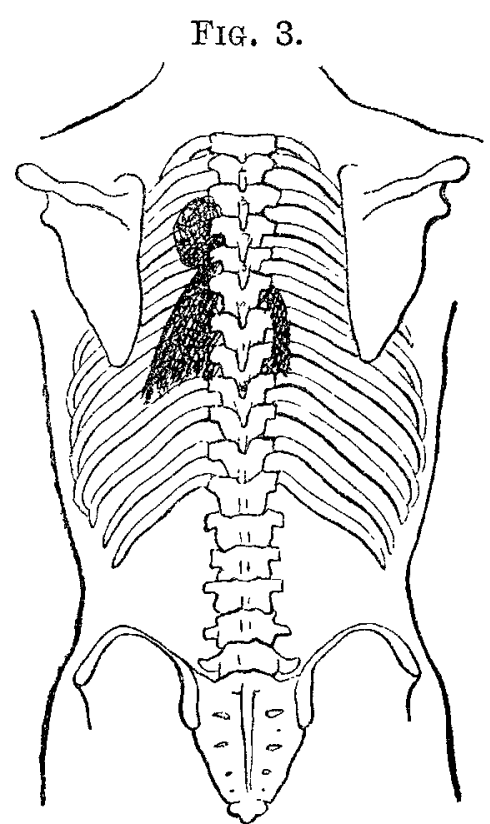

The shadow of the aneurysm is seen above the heart on the left side extending from the third to the fifth dorsal vertebra.

the aorta. The principal symptoms were pain, pulsation to the left of the heart in front, and paralysis of one vocal sord. On examination by the rays the posterior view showed the aneurysm very plainly. The shadow was very definite, situated above the shadow of the heart, and its outer border was sharply defined by a well-marked convex border. When viewed from the anterior the appearances were not so plain, but an ill-defined shadow could be seen which was continuous with that formed by the heart. The appearances of the aneurysm are shown in Fig. 3. This case was shown by Dr. Bezly Thorne at the Clinical Society on Feb. 26th, 1897.' CASE 4.- This case, which was kindly brought to me by Dr. Biss, shows the appearance of a new growth in the chest which had displaced the heart. The patient had been under Dr. Biss's observation for a long time, and the symptoms and physical signs made it probable that the condition was that of a new growth complicated by some pleural effusion, though at one time the possibilities of an aneurysm had also been considered. The patient's chest had been tapped twice; the first time some fluid was drawn off, but at the second operation, which was performed a few days before she was examined by the rays, no fluid was obtained. On examining the patient with the rays and a fluorescent screen the left side of the chest was seen to be quite dark as high up as the second rib. Above this level there was a lighter area, but not so light as normally should be, evidently corresponding to the apex of the left lung. The heart was very much displaced; its convex right border was well marked and at one spot reached almost to the nipple line. The origin of the aorta, displaced a good deal to the right of the sternum, was also well seen, and its pulsations were distinctly visible (Fig. 4).

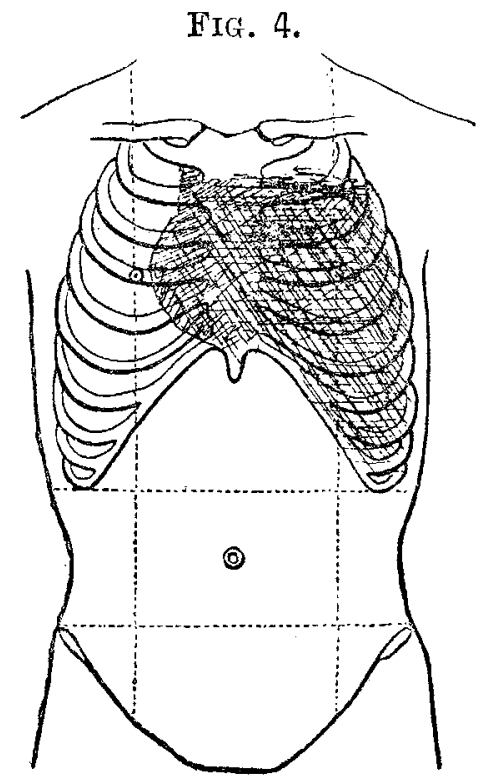

Showing the dark shadow of the left side of the chest with displacement of heart and aorta to the right.

I also saw several cases with Dr. Chapman of which I have unfortunately not preserved diagrams. Of course, in all such cases a positive result is of greater value than a negative one, as it may always be said that the aneurysm is either too small or situated in such a position that it did not show, but at the same time when a patient complains of thoracic symptoms and physical signs prove nothing it is in many cases a useful corroboration to know that the Roentgen rays show nothing also, and such a result has in several cases further strengthened the diagnosis.

Queen Anne-street, $w$.

\section{LACERATIONS OF THE OS UTERI, VAGINA, AND PERINEUM IN SYPHILITIC WOMEN.}

BY JOHN A. SHAW.MACKENZIE, M.D. LOND.

MRs. Boyd's letter in 'THE LANCET of March 27th, while emphasising the fact that pneumonia is not unfrequently met with in syphilitics, introduces a point which has attracted my attention. I refer to the fact that in women obviously syphilitic, or whose husbands have suffered from syphilis previously to marriage, lacerations of the os, vagina, and perineum are not unfrequent. Such accidents, including uterine rupture, are probably more than coincidences, and 
syphilis may possibly account for such when the accoucheur is in no way to blame. The following cases I have noted.

CAsE 1.-A woman, aged thirty-nine years, complained of pelvic pain and backache. She had suffered from discharge for twelve months. She had had eight children; five had died, and there had been three still births and one abortion. She was suffering from prolapsed uterus; the perineum was absent, and she stated that forceps were used in one of her confinements. The pharynx was ulcerated.

CAst 2.-This patient three years ago had a bad confinement and the perineum was torn. She made a tedious recovery, the lochia lasting five weeks. During her pregnancy the hair fell out and she bad suffered from ulcerated throat since. The uterus was prolapsed.

CASE 3.- This patient, aged thirty years, suffered from falling womb and discharge since the birth of a child ten years ago. There had been two live births and two abortions. She is subject to sore-throats and the pharyox is ulcerated. The vaginal mucous membrane shows a hyperæmic, patchy, measly condition. The lips of the urethra are in a purple, swollen condition. The perineum shows the cicatrix of previous repair, but is thin and papery, and the uterus is prolapsed.

CASE 4.-This patient, aged forty-five years, had been married twenty-six years. Her husband died from hemiplegia some years ago. One child was born twenty-five years ago, but died in infancy. The patient is now out of health, is suffering from menorrhagia, erosion of the os, profuse leucorrhcea, excoriation of the vagina, prolapse of the uterus, and ulcerated tags of previous rupture of the perineum.

CASE 5.-This patient had been married twice. Her first husband died from cerebral trouble. By him she had four children and one abortion. In three months from the second marriage abortion occurred, followed by eruption on the skin attributed to fish diet. The pharynx and tonsils are now excoriated and the voice is hoarse, while there is scattered acne on the back. Perineorrhaphy was performed after her first confinement.

CASE 6.-This patient complained of agony in intercourse She has superficial sores of the internal labia, vaginitis, and endometritis. The pharynx is ulcerated and the glands are enlarged in the groin. The cicatrix of a repaired perineum is exquisitely tender to the touch.

CASE 7.-This patient, aged twenty-eight years, complained of pain in the back and groin. She bad been married nine years. There had been four live births and one abortion. She had suffered from discharge for eight years. She was regular, but lost a great deal. Her hair fell out during the last conception, which ended in abortion. She had sore-throats at the same time, and the pharynx is now ulcerated. She has always lost a great deal of blood at her confinements. The cervix is split and everted.

CASE 8.-This patient was a woman, aged fifty years. Two girls were born in the first two years after marriage. Then the husband was very ill with " rheumatic fever." An abortion followed, then a live bixth, then an abortion, and then two live births. The confinements have always been bad, with six weeks of lochia. After the second girl was born bleeding continued for three months. She now complains of abdominal and rectal pain. On vaginal examination the os uteri was found to be split and tethered to the vagina by bands in every direction, and the rectum is drawn in.

I would point out in connexion with such cases that labour is often protracted from uterine inertia, often necessitating forceps. The post-partum hæmorrhage is profuse and the lochia are prolonged. It is not very uncommon to meet with adhesions of the os uteri to the vagina, of increasing obstructive dysmenorrhœa, and sterility after one conception in parous women. The fibrous adhesions and fibroid condition met with in dilating the cervical canal are well known. Syphilitic stricture of the cervical canal or os uteri is apparently analogous to syphilitic stricture of the urethra in the male, and all the above-mentioned conditions may well illustrate some of the less ostensible symptoms of syphilis in parous women.

A further question follows. Why do plastic operations in women, undertaken with so much care and skill, often fail? The value of mercury in so many cases of pelvic disease in parous women not only testifies to a syphilitic basis, but probably makes it essential that mercurial treatment in many cases should go hand in hand with operative procedure.

Grosvenor-street, W.

\section{A CASE OF ANKYLOSIS OF ALL THE' JOINTS WITH COMPLETE CLOSURE OF THE JAWS, IN WHICH THE. POWER OF MASTICATION WAS RESTORED BY DIVISION OF THE NECKS OF THE LOWER JAW :}

WITH SOME REMARKS ON THE OPERATIVE TREATMENT OF CASES OF ANKYLOSIS OF THE TEMPORO. MAXILLARY JOINT,

BY CHARLES A. MORTON, F.R.C.S. ENG.

SURGEON TO THE PRISTOL GENERAL HOSPITAT AND PROTESSOR OF SURGERY IN UNIVERSITY COLLEGE, BRISTOL.

A MAN, aged fifty-seven years, was sent to we at the Bristol General Hospital by Mr. W. F. Carter, of Bristol, in October, 1896. In all the joints movement was limited, and in most there was complete fixation. The spine and head were perfectly rigid. Deformity was marked both in the large joints and in those of the hands and feet. In some joints where slight movement was possible there was coarse grating, and around a few joints distinct ostesphytic out. growths were present. Muscular wasting was extreme; the skin of some of the fingers was glossy, and some of the nails were of extraordinary thickness. The thickening of the nails was not present in all the fingers. The joint troubles began fourteen years previously in the knees, and the fingers were affected after the larger joints. He was able to walk with sticks until nine years ago. For the last six years he had been confined to bed and unable to feed himself, and for four years he had been unable to open his jaws and therefore unable to take solid food, and had simply sucked fluids between his teeth. He had had no joint trouble in early life, nor was there any family history of such disease. The following is a description of the condition of all the joints. Both knees were absolutely fixed at a right angle. The bony outline was very prominent from the wasting of the muscles, but no osteophytic growths were discovered. The tendons in the popliteal space did not feel contracted. No movement was detected in either hip.joint There was limited movement in the left ankle, but the right ankle was almost completely fixed. All the toes of the left foot except the great toe were hyper-extended (some to a right angle with the dorsum), and the heads of the metatarsal bones from which they were displaced could be felt from the sole. The middle three toes of the right foot were in the position of hammer-toes. The nails on several toes were of extraordinary length and thickness. The left wrist was flexed almost to a right angle with the forearm and quite ankylosed. The fingers of the left hand were all flezed at the metacarpo-phalangeal joints, and there was marked deviation to the ninar side. Movement in the finger joints was much limited. There was marked osteophytic outgrowth about the heads of the metacarpal bones. The nails on some of the fingers were almost normal, on others they formed a horn mass half an inch in thickness, and the skin. of the fingers was glossy. There was no grating in any of the joints. The left thumb was also flexed at the metacarpophalangeal joint, but was hyper-extended at the terminal one and movement in its joints was as limited as in the fingers. The right wrist was slightly flexed and very little movement was possible in it. All the fingers of the right hand were hyper-extended at the metacarpo-phalangeal joint, flexed at the middle phalangeal joint, and hyper-extended again at the terminal joint. 'Ihere was hardly any movement possible in any of the joints, and osteophytic outgrowths were present on the dorsal aspect of the digital extremities of the first phalanges forming the middle phalangeal joint. The position of the right thumb was the same as the left. There was slight grating in its metacarpo-phalangeal joint. The left elbow was quite ankylosed and was much more flexed than a right angle with the upper arm. In the right elbow there was slight movement which was painful, and there were some sharp osteophytic outgrowths from the inner

1 A paper read before the Bath and Bristol Branch of the British Medical Association. 